\section{A contribuição dos trabalhadores na consolidação dos serviços municipais de vigilância sanitária}

\author{
Workers' contribution to the consolidation \\ of municipal health surveillance services
}

Vanda Garibotti 1

Élida Azevedo Hennington 1

Lucilda Selli 1

\author{
1 Programa de Pós- \\ graduação em Ciências \\ da Saúde, Universidade \\ do Vale do Rio dos Sinos, \\ São Leopoldo, Brasil. \\ Correspondência \\ V. Garibotti \\ Programa de Pós-graduação \\ em Ciências da Saúde, \\ Universidade do Vale \\ do Rio dos Sinos. \\ Rua Dr. Otávio Santos 330 , \\ apto. 208, Porto Alegre, RS \\ 91210-000, Brasil. \\ vandagarib@hotmail.com
}

\begin{abstract}
This study aimed to expand knowledge on the role and possible contribution of workers in the consolidation of health surveillance services in three municipalities in Greater Metropolitan Porto Alegre, Rio Grande do Sul, Brazil. The research used a qualitative methodology based on focus groups and participatory observation. The resulting data were categorized by content analysis. The results pointed to precarious management of the health surveillance services. The main problems were deficiencies in staff education and training, precarious work conditions, lack of resource allocation autonomy and selfmanagement, in addition to prioritization of actions with a limited scope, focused on the control and oversight of products and services, to the detriment of broader activity with other determinants of the health-disease process. Despite this situation, most staff members seek further training on their own and oscillate between the pursuit of alternatives to overcome the difficulties and moments of frustration and discouragement.
\end{abstract}

Sanitary Surveillance; Resources Management; Workers

\section{Apontamentos para introdução}

As conseqüências diretas e indiretas da globalização, tais como, uma maior circulação e interação de pessoas, animais, produtos e serviços e a rápida disseminação de patógenos, além da precarização das condições de vida e de trabalho reafirmam a necessidade de um Estado forte e capaz de interferir nas relações econômicas e sociais com o objetivo de preservar a vida e o ambiente, os interesses da coletividade e das comunidades. Esses fatores têm levado a uma maior valorização das ações de vigilância sanitária no país, tornando imprescindível a qualificação dos serviços para o cumprimento integral de suas atribuições.

Historicamente, as ações de caráter fiscalizatório foram priorizadas e alcançaram maior visibilidade no campo da vigilância sanitária. Este tipo de intervenção é legitima enquanto papel regulador do Estado, porém insuficiente para responder às necessidades de saúde e melhoria das condições de vida da população. Por outro lado, a maior autonomia financeira e administrativa alcançada com a criação da Agência Nacional de Vigilância Sanitária (ANVISA) em 1999, não modificou a realidade nos estados e municípios. Ainda hoje observa-se uma atuação marcada pela visão parcial de risco, voltada eminentemente para o controle e fiscalização de produtos e serviços, excluindo de seu campo o ambiente e a saúde do trabalha- 
dor. A maioria das administrações locais acabou incorporando a vigilância sanitária num conceito limitado, organizando os serviços de forma fragmentada, não promovendo a integração das áreas de atuação e muito menos o planejamento sobre as prioridades e necessidades de saúde 1. Desse modo, consolida-se o antigo modelo em detrimento da proposta de implantação de uma concepção ampliada de vigilância da saúde como possibilidade de redefinição das práticas sanitárias, principalmente no nível municipal 2.

Nesse contexto, os trabalhadores da saúde ora são apontados como potenciais sujeitos de mudança e de reformulação das práticas de saúde, ora são considerados como "um fardo", "um problema" a ser resolvido com medidas burocráticas 3 . Muito pouco se tem estudado ou experienciado em relação a novas formas de gestão que considerem os trabalhadores "sujeitos sociais" conforme afirma Campos 4, e não apenas como "mero recurso".

Este estudo teve como objetivo principal aprofundar o conhecimento sobre o papel e as possibilidades de contribuição dos trabalhadores para a consolidação dos serviços de vigilância sanitária, com base na análise de três serviços da região metropolitana de Porto Alegre, Rio Grande do Sul, Brasil.

\section{O percurso metodológico}

A metodologia é qualitativa e teve como sujeitos de pesquisa os trabalhadores de vigilância sanitária de três municípios da Região Metropolitana de Porto Alegre que desenvolviam ações básicas de vigilância há no mínimo dois anos. Esses municípios foram classificados de acordo com o índice de desenvolvimento social e econômico (IDESE) 5 . Trata-se de um índice sintético elaborado e utilizado pela Fundação de Economia e Estatística do Estado do Rio Grande do Sul e que agrega informações municipais sobre quatro blocos de indicadores: "domicílio e saneamento", "educação", "saúde" e "renda". Foram escolhidos dois representantes com IDESE considerado baixo, dois municípios com médio desenvolvimento e dois municípios com IDESE alto. Para a seleção final dos três municípios foram consideradas a proximidade geográfica e a autorização dos gestores municipais, no intuito de facilitar o acesso e o desenvolvimento do estudo.

Participaram da pesquisa 26 trabalhadores que atuavam de forma direta nos serviços, inclusive os coordenadores (gerentes). Destes, a metade tinha nível superior e os demais nível médio. Dos profissionais de nível superior, apenas seis tinham dedicação exclusiva ao serviço. Como técnicas de investigação foram utilizados o grupo focal e a observação participante. Em cada um dos serviços foram realizadas reuniões que seguiram roteiros semi-estruturados, previamente elaborados, para discussão dos seguintes grandes temas: "formação acadêmica e qualificação profissional", "configuração da vigilância sanitária nos três níveis de governo", "impacto das ações de vigilância sanitária" e "papel e contribuição dos trabalhadores na consolidação dos serviços de vigilância sanitária”.

Nos três encontros realizados, um reuniu somente profissionais de nível médio, outro, profissionais de nível superior e um terceiro encontro, toda a equipe (incluindo o gerente). Esta conduta foi tomada no sentido de tentar eliminar qualquer tipo de coerção ou constrangimento relacionados à presença de colegas exercendo cargos hierarquicamente superiores. Num dos municípios não foi possível fazer esta separação devido ao pequeno número de profissionais no serviço. Observações participantes foram realizadas em dois momentos para cada equipe selecionada.

As discussões nos grupos focais foram gravadas em fita cassete e posteriormente transcritas para a análise dos dados. Os pronunciamentos foram tratados por meio de análise de conteúdo proposto por Bardin 6 e Minayo 7 . No processo de tratamento inicial dos dados, cada município foi considerado uma unidade de contexto por suas características históricas e sócio-econômicas. Os textos transcritos foram classificados em unidades de registro, segundo pressupostos estabelecidos a priori e outros novos que surgiram durante o processo de análise. Em torno dessas unidades foram sendo agrupados os temas; em seguida fez-se o enxugamento da classificação por temas mais relevantes, aglutinando temas comuns em relação aos diferentes municípios, porém observandose as diferentes unidades de contexto onde foram produzidos e, posteriormente, realizandose comparações entre eles para a análise final.

Esta pesquisa foi submetida e devidamente aprovada pelo Comitê de Ética em Pesquisa da Universidade do Vale do Rio dos Sinos, atendendo aos critérios previstos na Resolução $n$. 196/96 do Conselho Nacional de Saúde.

\section{Contextualizando os resultados}

No município com o menor IDESE, as condições de trabalho eram as mais precárias e per- 
cebeu-se também uma baixa auto-estima dos profissionais. Neste serviço ficou evidente a dificuldade dos trabalhadores em lidar com os enormes problemas sociais com os quais se deparavam no dia-a-dia de sua atuação profissional. Apesar disso, talvez devido às imensas dificuldades e ao fato de tratar-se de um grupo reduzido de profissionais, havia um forte espírito de equipe e não foram evidenciadas grandes disputas internas de poder.

No serviço de IDESE intermediário sobressaíram os conflitos decorrentes das relações interpessoais e das disputas internas de poder entre os profissionais. É também o serviço com maior diversidade de vínculos empregatícios, de carga horária e de maiores diferenças salariais.

O município com IDESE mais alto era também o mais populoso e que tinha o serviço que alcançou maior visibilidade perante a população segundo seus próprios profissionais, conseguindo inclusive, conquistar o status de "Departamento de Vigilância em Saúde", dentro do organograma da Secretaria de Saúde. A autoestima dos trabalhadores era a mais elevada em relação aos demais municípios estudados.

Surpreendentemente, nos três municípios a questão salarial não foi abordada com grande ênfase pelos profissionais, não sendo sequer mencionada no município com menor IDESE.

$\mathrm{Na}$ análise dos depoimentos, houve muitas similaridades e poucas contradições ou choque de opiniões entre os trabalhadores dos diferentes municípios. Os problemas sociais e econômicos existentes e suas repercussões no fazer diário foram enfatizados de forma semelhante nos três serviços.

A seguir, serão apresentados os resultados referentes a quatro grandes unidades de análise: "formação acadêmica e qualificação profissional", "a vigilância sanitária nas três esferas de governo", "gestão de recursos, processos e condições de trabalho" e "impacto e consolidação das ações de vigilância sanitária”.

\section{Formação acadêmica}

\section{e qualificação profissional}

Constatou-se, logo de início, que a maioria dos trabalhadores não tiveram formação específica sequer para atuar na área da saúde e, muito menos, na vigilância sanitária. Nem mesmo o pessoal de nível superior teve contado com conteúdos específicos da área durante o ensino de graduação. A maioria dos cursos da área de saúde e afins não abrange a temática da vigilância sanitária em seus programas 8 .

Segundo os relatos, o ofício foi aprendido na prática, na vivência dentro do serviço e por meio de iniciativa pessoal, pelo estudo da legislação sanitária, realização de cursos específicos etc. De modo geral, não existe uma política de educação continuada por parte das gestões municipais - observou-se que, ao mesmo tempo em que não havia impedimento da busca pessoal por aprendizagem, não existia estímulo ou uma gestão que valorizasse de fato e contemplasse a qualificação, a capacitação e o aperfeiçoamento profissional. A preocupação dos trabalhadores evidencia-se no seguinte depoimento: "nos meus 16 anos de serviço público, posso contar nos dedos os cursos que nos convidaram a participar ...".

A formação dos profissionais de vigilância se dá num processo, muitas vezes, empírico, descontínuo e assistemático e, não raramente, sem comprometimento com o conhecimento técnico e eficácia da ação 9 . A formação defronta-se com um conjunto de limitações que advém do tradicional isolamento institucional da vigilância sanitária no contexto da saúde e até do desconhecimento da função da vigilância sanitária como ação de saúde 8 .

Apesar disso, a metade dos profissionais de nível superior que participou da pesquisa tem especialização na área de saúde por iniciativa própria, devido à exigência e complexidade das funções que desempenham.

Os profissionais de nível médio representam mais da metade da força de trabalho nos municípios estudados, e a maioria busca capacitar-se, pois percebem a abrangência das ações de vigilância, bem como sua relevância para o Sistema Único de Saúde (SUS): “a tecnologia avança muito rapidamente, imagine nos estabelecimentos de saúde, pegamos uma gama enorme de serviços, creches, asilos, clínicas, ... as clínicas cada uma com equipamentos diferentes, tomografia, fisioterapia ...".

Entretanto, como a busca pelo conhecimento é maior por iniciativa pessoal, usualmente os profissionais de nível superior têm maior acesso em relação aos de nível médio que, comumente, estão lá na ponta desempenhando as ações e possuem menos tempo, condições financeiras e estímulo para o aperfeiçoamento técnico-científico.

Cabe ressaltar, porém, as iniciativas de incentivo à educação continuada por parte da ANVISA ao inserir em sua estrutura o Comitê de Política de Recursos Humanos, bem como a conquista de espaço da vigilância sanitária, incluída como área temática nos congressos da ABRASCO (Associação Brasileira de Pós-Graduação em Saúde Coletiva), e a implantação de cursos de especialização em diversas instituições de ensino, como movimentos que têm ge- 
rado possibilidades de acesso e incremento do conhecimento teórico-conceitual e prático, porém ainda distantes e insuficientes para a maioria dos profissionais, principalmente no nível municipal.

É fundamental para o desenvolvimento e fortalecimento dos serviços o investimento na formação profissional, na capacitação técnica e na apropriação de novas tecnologias, sob pena das ações de vigilância se transformarem num verdadeiro faz-de-conta e da perpetuação de serviços inoperantes e/ou sem efetividade diante do setor regulado, detentor de poder econômico e tecnológico, e das prementes necessidades de saúde da população.

\section{A vigilância sanitária nas três esferas de governo}

Em relação ao sistema de vigilância sanitária, os profissionais conheciam melhor a estrutura municipal e a estadual, com as quais lidam diretamente; já a estrutura federal conheciam pouco e, geralmente, apenas através do site, disponível on-line. Referiram o distanciamento da ANVISA e a falta de canais ágeis de comunicação e resolução de demandas entre os diferentes níveis do sistema. "A ANVISA avalia um produto, quando pede para recolher passa para os 27 estados, no caso do Rio Grande do Sul para a Divisão Central, a central passa para as regionais, que depois passa para os municipios, isso dá 40 a 50 dias, período em que a população fica sujeita ao risco do consumo! Se tem internet, por que não passa direto? Com cópia para o estado e município?".

Os serviços municipais, por unanimidade, apontaram o deficiente funcionamento da estrutura no nível estadual, incapaz de cumprir seu papel de cooperação técnica e financeira aos municípios: "eu cansei de ir na la CRS [Coordenadoria de Saúde] pedir alguma informação e constatar que eles tinham menos conhecimento sobre o assunto que o nível municipal...”, “...quando não perdem os documentos, enviam com atraso, às vezes os produtos já venceram”. “...sabemos que eles também têm dificuldades, falta pessoal, veículos, computadores, linhas telefônicas".

O serviço estadual de vigilância sanitária tem atribuição de inspeção sobre o processo produtivo, produtos e serviços, laboratórios de controle de qualidade, sistemas de informação, desenvolvimento de recursos humanos, supervisão e cooperação com as secretarias municipais e, ainda, a implementação da descentralização das ações para os municípios, sendo portanto a executora principal das ações de média e alta complexidades. A atual estruturação da vigilância sanitária nas secretarias estaduais de saúde não se coaduna com as competências e as funções que o sistema atribui a esse nível de governo 10 .

A atuação da recém-criada Secretaria de Vigilância em Saúde, Ministério da Saúde, ainda não conseguiu repercutir sobre as gestões municipais e não foi sequer citada pelos trabalhadores dos municípios pesquisados.

A efetividade das ações de vigilância garantidas pela Lei Orgânica da Saúde depende da implementação de um Sistema Nacional de Vigilância Sanitária (SNVS) que funcione na prática, com atribuições acordadas e definidas entre os três níveis, e canais permanentes de interlocução e retroalimentação.

\section{Gestão de recursos, processos}

\section{e condições de trabalho}

De acordo com os depoimentos, as ações de vigilância sanitária não eram prioridades na gestão municipal. Os profissionais de dois serviços municipais denunciaram que, embora no discurso os gestores locais defendam as ações de prevenção e promoção à saúde, incluídas as ações de vigilância sanitária, na realidade o que se percebe é um total abandono do setor, ficando o serviço de vigilância à própria sorte, muitas vezes sem investimentos de qualquer tipo. Os depoimentos abaixo revelaram os sentimentos dos profissionais acerca disto: " $A v i$ gilância é cantada em prosa e verso como muito importante, mas fica no discurso..." "Os gestores municipais pactuam as atividades de vigilância sanitária para receber recursos financeiros; depois que está instalado o serviço e vêm os recursos: os carros vão para um lado, os computadores para outro, eles têm enorme demanda na assistência e desviam os recursos".

A vigilância sanitária apresenta hoje uma configuração profundamente desigual - no nível central, a ANVISA possui autonomia administrativa e financeira, porém os serviços pertencentes às administrações diretas (estados e municípios) têm reduzido poder administrativo, o que dificulta a utilização dos recursos repassados e a participação na definição do funcionamento do sistema como um todo 11 .

Falta autonomia no uso dos recursos financeiros, sejam os provenientes do Piso de Atenção Básica (PAB), sejam os recursos do incentivo à descentralização ou mesmo aqueles arrecadados pelo próprio serviço, o que fica evidente nos depoimentos dos trabalhadores: "Apesar de a vigilância sanitária não ter fim arrecadador, ela arrecada e para onde vão 
estes recursos? Para o caixa único da prefeitura. O mesmo ocorre com as verbas repassadas pela municipalização ... . Não gerenciamos esse dinheiro...".

Em relação ao provimento dos trabalhadores, embora existam pequenas diferenças entre os serviços, as coordenações, no geral, têm de lidar com distintas formas de vínculo empregatício, carga horária, diferenças de escolaridade e salariais dos profissionais de sua equipe. Observe-se o depoimento do coordenador de um serviço: “Aqui no meu município existe a política do estagiário, selecionados por eles é claro, amigo do vereador, vizinho do prefeito ... sem contar os cargos de confiança e os fiscais cedidos do estado - que possuem diferente carga horária e salário...".

É consenso o fato de que para se implantar um sistema de vigilância sanitária é fundamental a definição de uma política satisfatória de recursos humanos que atenda a cada nível de governo. Na prática, o que se tem verificado é o provisionamento de recursos humanos sem estabilidade e sem prerrogativas inerentes à função reguladora, dentre as quais, cabe destacar, a estabilidade e a dedicação exclusiva no emprego. A conseqüência disto é a alta rotatividade de profissionais gerando instabilidade nos quadros e uma absorção acentuada dos técnicos mais qualificados pelo setor privado, mais competitivo e atraente 9 . A reforma no aparelho do Estado flexibilizou as formas de provimento de pessoal, e as diferentes formas de contratação e pagamento de pessoal distanciam-se das necessidades de vínculo para o setor público de saúde 12,13 .

Para muitos gestores, a temática de pessoal em saúde ainda se restringe às necessidades de contratação e alocação de pessoal em função dos limites impostos pela Lei de Responsabilidade Fiscal. Este quadro aponta uma conformação que explicita contradições e conflitos entre dois projetos políticos: o neoliberal e o da reforma sanitária 14 , impondo aos trabalhadores a luta pela manutenção das conquistas trabalhistas, sob pena de paulatinamente haver maior precarização das condições de trabalho e vínculos cada vez mais enfraquecidos, comprometendo a construção e consolidação do SUS.

Os profissionais denunciaram a falta de infra-estrutura e ausência de condições mínimas para um trabalho condigno. Faltam elementos básicos de um adequado ambiente de trabalho como: espaço físico, mobiliário, veículos, além de equipe mínima, pessoal de apoio administrativo, de limpeza, motorista. A falta de estrutura aparece em menor ou maior grau nos três municípios: “É complicado viver num amontoado de gente - 8 pessoas em $9 m^{2}$ - não temos mesa própria ou armário para guardar os documentos..." (município com IDESE baixo).

"Nós estamos há três meses sem pessoal de limpeza, quem faz a faxina é uma pessoa desviada da equipe da Dengue" (município com IDESE intermediário).

"Eu chego, separo os processos, denúncias de um bairro, quando vou pegar o veículo, cadê?" (município com IDESE alto).

A ausência de assessoria jurídica aos serviços foi destacada de forma unânime como um dos principais fatores limitantes para o desenvolvimento e efetividade das ações regulatórias, já que estas lidam diretamente com a legislação sanitária, exigindo ações fundamentadas em dispositivos legais e processos adequados à forma jurídica.

Apesar do fortalecimento dos serviços de vigilância sanitária nos últimos anos, a autonomia na busca da qualidade de produtos e serviços mediante o cumprimento das normas sanitárias é ainda restrita. Muitas ações têm repercussões econômicas e sociais que contrariam interesses de grupos locais ou intervêm em questões do âmbito de outras secretarias ou órgãos públicos. O serviço de vigilância sanitária passa a regular outros serviços públicos municipais (creches, asilos, unidades de saúde) e estaduais (como o sistema público de abastecimento de água) e, muitas vezes, os profissionais sofrem pressão político-administrativa por parte do poder executivo e/ou legislativo municipal. As interferências econômicas e político-partidárias evidenciaram-se nos depoimentos: "Nós não interditamos um estabelecimento ou apreendemos produtos por livre e espontânea vontade, a gente leva pro diretor, ele vai até o local, analisa, autoriza ou não. ... se um estabelecimento for penalizado com multa ou interdição, sempre tem um político que vem interceder...".

Se por um lado, aproximar essa atividade da população possibilitou um melhor controle e maior possibilidade de intervenção, o que era objetivo da descentralização da vigilância sanitária, por outro, tornou-a mais vulnerável às pressões econômicas e políticas 9 .

Em relação à gestão dos processos de trabalho, faltam espaços de escuta, de participação e de tomada de decisões que envolvam os profissionais de saúde. Os trabalhadores sentemse desprestigiados e sem autonomia, seja pela limitação no uso dos recursos e/ou principalmente pelo pouco espaço de participação nas decisões. Os profissionais clamaram pela criação de mecanismos de participação no proces- 
so decisório de trabalho. Ao tomarem contato com novas situações e desafios, querem ser ouvidos e iniciar mudanças no sentido de adequar o serviço às necessidades locais de saúde: "Estamos na ponta, fazemos a frente, levamos a realidade da rua e não somos ouvidos...”; “...é muita distância entre quem planeja e quem executa...". Saliente-se que estes depoimentos se deram em dois serviços, nos encontros dos grupos de nível médio, onde não estavam presentes os coordenadores.

As prioridades detectadas e as demandas encontradas pelos profissionais na labuta diária têm pouco espaço no planejamento e programação dos serviços. Os municípios pactuam com o estado as ações de vigilância sanitária a serem desenvolvidas e o "pacote das ações" vem pronto, muitas vezes distante da real necessidade de um bairro ou município. A vigilância sanitária estadual que, tradicionalmente, oferece um serviço de caráter regulatório, priorizando ações sobre os setores de produtos e serviços, reforça este modelo no momento da descentralização das ações para os municípios.

A Lei Orgânica da Saúde amplia as responsabilidades da vigilância sanitária, anteriormente restritas a produtos e serviços para o ambiente e a saúde do trabalhador; contudo a mudança da legislação não implicou a mudança do processo de trabalho da vigilância, que continuou desarticulada das demais atividades desenvolvidas pelo setor público de saúde e demais secretarias municipais. Preparada para atuar em programas compartimentados (alimentos, serviços de atenção à saúde, portos, aeroportos e fronteiras), seu planejamento é direcionado para as regiões de melhor nível sócio-econômico da cidade, sem propostas para atuação em vilas, favelas ou zonas rurais 1 . As gestões municipais não conseguiram integrar ações ou remodelar as práticas levando em conta as prioridades locais de saúde, planejando e organizando o serviço com base em operações integradas aos demais serviços da rede municipal, construindo um novo modelo que se aproxime da vigilância em saúde 2,15 .

O modo como se estruturam e se gerenciam os processos de trabalho é um dos temas mais problemáticos para o setor saúde 16. A fragmentação do trabalho, a gestão pouco democrática, a divisão entre os que pensam e os que executam têm favorecido a desresponsabilização, o descompromisso e os acordos velados entre os envolvidos nos serviços ${ }^{3}$.

Vários autores defendem formatos de gestão que busquem a democratização das instituições, possibilitando a participação e o fortalecimento dos profissionais enquanto sujei- tos, o que acarretaria ganhos tanto na satisfação dos profissionais quanto para as instituições e, principalmente, para os usuários do sistema $3,16,17,18$.

\section{Impacto e consolidação das ações de vigilância sanitária}

O modo de produção centrado na forma de mercadoria mostra-se incapaz de se auto-regular e tende a subtrair os direitos fundamentais à saúde e à vida. O reconhecimento da vulnerabilidade do consumidor no mercado de consumo de bens materiais e imateriais, gradativamente potencializada pela assimetria de informação, justifica e sustenta a obrigatoriedade da regulação das práticas do mercado no interesse da saúde humana e ambiental 19.

Os profissionais relataram melhorias obtidas por meio das ações de vigilância sanitária: "Melhoramos a qualidade dos produtos e serviços"; "dá para fazer a comparação entre o antes e o depois ... . Intensificamos a busca de carne clandestina nas Vilas? Para quê? Impedir que o trabalhador compre carne barata? Não! Garantir ao trabalhador um produto de qualidade".

Apesar da implantação recente dos serviços nesses municípios, os trabalhadores apontaram mudanças significativas, principalmente no controle do comércio de alimentos, atividade tradicionalmente desenvolvido pela vigilância sanitária. Contudo, referiram igualmente que o impacto das ações de vigilância sanitária precisa ser ampliado; os profissionais revelaram a sua preocupação com a parcialidade das ações centradas no controle de produtos e serviços em detrimento dos outros determinantes do processo saúde-doença e a baixa efetividade junto à população carente, com pouca ou nenhuma escolaridade.

Depoimentos quanto à pouca efetividade das ações junto à população de baixa renda ocorreram nos três municípios, porém foi mais enfatizada no município com menor IDESE. Os profissionais expressaram sofrimento ao sentirem-se impotentes frente à impossibilidade do cumprimento de normas sanitárias, em decorrência da diversidade e gravidade dos problemas sociais, principais determinantes do processo saúde-doença na periferia das cidades capacitados que foram para atuar como fiscais sanitários. Notou-se também pouca experiência e iniciativa na articulação com outros setores/segmentos da prefeitura, órgãos e entidades governamentais e não-governamentais para a solução de problemas locais. Os trabalhadores acompanhavam as condições de higiene de produtos e serviços, disseminavam infor- 
mações, sugeriam formas de parcerias etc., mas tinham consciência e deixavam claro que seria preciso bem mais. Os relatos ilustram esses sentimentos: "Muito trabalho informal, em qualquer fundo de quintal tem uma fabriqueta, todo mundo está desesperado sem dinheiro, sem trabalho...; as pessoas moram em áreas invadidas, áreas verdes, sem saneamento básico e lá abrem um mercadinho... o que fazer? Ir lá fechar? Orientar para que ele alcance um minimo de qualidade? Então os estabelecimentos regulares reclamam que as normas existem só para eles!".

Os trabalhadores expressam no desenvolvimento de seu trabalho não só questões objetivas, mas seu modo específico de compreender e realizar seus projetos, seu jeito de enxergar a vida, seus desejos, suas vontades, medos e aflições, sua subjetividade. Recursos humanos em saúde nada mais são do que gente que cuida de gente, isto é, são pessoas que muitas vezes mantêm relações de troca de conveniências com os usuários em situações que as expressões de subjetividade se fazem presentes de ambos os lados 14. A captura total do autogoverno nas práticas de saúde é impossível pela própria natureza tecnológica desse trabalho. $\mathrm{O}$ trabalho vivo se expressa como autogoverno e tem sido e será o lugar do novo e das possibilidades, estando aberto para o que nele há de indeterminado, do que se define em ato em produção permanente, nos espaços das intersecções, produções e consumo 16 .

Apesar da mecânica deformadora das escolas, o funcionamento burocratizado dos serviços e a dinâmica individualista da sociedade serem instâncias que contribuem para distanciar o trabalhador do seu apego à obra 20, o exercício da autonomia revela-se na ação, no trabalho vivo em ato, principalmente no contato entre o trabalhador de vigilância sanitária e o objeto de seu trabalho. Ali, apesar da legislação a ser cumprida - normas sanitárias, normas técnicas, normas da instituição - no encontro do profissional com outros profissionais, com usuários ou representantes do setor regulado foi possível constatar a atuação do trabalhador enquanto sujeito e sua condição de profissional como potência para a mudança - podendo estabelecer relações de orientação/punição ou de orientação/compromisso/parceria na busca de maior qualidade do produto, serviço ou ambiente, criando novas maneiras de acolher, orientar e se posicionar frente aos usuários e aos problemas de saúde, resistindo à acomodação por meio de atos no dia-a-dia do trabalho, consolidando o serviço de vigilância sanitária.
Os trabalhadores acreditam na relevância das atividades educativas e de comunicação em saúde para efetivar as práticas de vigilância sanitária, e demonstraram que as ações neste sentido têm origem no esforço pessoal dos profissionais. A elaboração de folders e cartilhas, o oferecimento de palestras para escolas e comunidades foram referidos como prática usual nos três municípios, sendo que um deles se utilizava muito do jornal local para divulgar o serviço e informações em saúde. Reconhecem que essas ações são insuficientes e precisam de maior investimento tanto na qualidade da comunicação quanto na intensidade.

Durante as observações participantes comprovou-se o caráter educativo dos trabalhadores e a mudança de postura do fiscal/policial para o orientador/parceiro na busca da qualidade de vida. Foi possível observar que no contato com o setor regulado, orientavam, faziam solicitações e só penalizavam em último caso.

A discussão, elaboração e proposição de normas sanitárias é uma prática de iniciativa também dos profissionais que, perante a necessidade de regulamentação, estudam e propõem normas adequadas à realidade local. Nesse sentido, os trabalhadores nos três municípios apontaram a necessidade urgente de mobilização para a revisão do Código Sanitário Estadual de 1974, que necessita de atualização, já que nos últimos trinta anos os avanços científicos e as mudanças sociais são consideráveis, necessitando de regulação sanitária compatível.

\section{Considerações finais}

Há que se encontrar estratégias junto aos segmentos menos privilegiados da população para fazer cumprir o tão discutido princípio da eqüidade. Questão que reflexiona a capacidade do serviço de vigilância sanitária de atuar em defesa da vida e não em resposta às demandas dos interesses econômicos. Uma possibilidade que já se vislumbra é angariar o envolvimento da sociedade na defesa de sua própria saúde, desde a elaboração das normas sanitárias até o controle social das políticas públicas de saúde, mediante o investimento intensivo nas práticas de educação em saúde por parte dos serviços, contribuindo para tornar cada usuário um sujeito, um cidadão mais autônomo e crítico, capaz de reivindicar seus direitos individuais e coletivos e lutar por maior qualidade de vida. Ou seja, não basta certo grau de poder do Estado para controlar os setores produtivos; a vigilância sanitária é de responsabilidade do Estado, mas também da sociedade civil 21 . 
Apesar da Lei n. 9.782/99 22 que define o SNVS reservar à esfera federal a definição das políticas e diretrizes do sistema de vigilância, no nível municipal o gestor em conjunto com os trabalhadores pode reorganizar e otimizar as ações de vigilância sanitária, reestruturando as práticas e o modelo de atenção à saúde de acordo com o modelo de vigilância da saúde, já proposto por vários estudiosos.

A falta de condições adequadas de trabalho não pode ser usada como pretexto para o não exercício da autonomia e do papel de sujeito de cada trabalhador, porém ela é real e geradora tanto de processos de acomodação e frustração, como também de processos criativos e estratégias de luta nos serviços. A consolidação dos serviços de vigilância sanitária é um processo em construção, porém avanços na área da saúde requerem inovação e ousadia, seja pela atuação dos trabalhadores, seja pelo estímulo na renovação dos processos de trabalho tanto na micro como na macroestrutura de gestão. Dar ouvidos a eles, os trabalhadores, eis um bom começo para potencializar a mudança.
Resumo

Este estudo teve como objetivo principal aprofundar o conhecimento sobre o papel e as possibilidades de contribuição dos trabalhadores na consolidação dos serviços de vigilância sanitária em três municípios da Região Metropolitana de Porto Alegre, Rio Grande do Sul, Brasil. Trata-se de uma pesquisa qualitativa que utilizou como técnicas o grupo focal e a observação participante. Os dados coletados foram sistematizados e categorizados por meio de análise de conteúdo. Os resultados apontaram a precariedade da gestão dos serviços de vigilância sanitária estudados. Os principais problemas identificados foram deficiências na formação e capacitação dos profissionais, precárias condições de trabalho, falta de autonomia na alocação de recursos e de autogestão do trabalho, além da priorização de ações de caráter restrito, voltadas para o controle e fiscalização de produtos e serviços em detrimento de uma atuação ampliada, dirigida para outros determinantes do processo saúde-doença. Apesar desta realidade, a maioria dos profissionais busca qualificação por conta própria e oscila entre a procura de alternativas para a superação das dificuldades $e$ momentos de frustração e desânimo.

Vigilância Sanitária; Gestão de Recursos; Trabalhadores

\section{Colaboradores}

Os autores contribuíram igualmente em todas as etapas de elaboração do artigo.

\section{Agradecimentos}

Aos trabalhadores da biblioteca da Escola de Saúde Pública, Rio Grande do Sul, por vossa prestimosa disponibilidade de colaboração. 


\section{Referências}

1. Magalhães MCC, Freitas RM. Apontamentos para a discussão da vigilância sanitária no modelo de vigilância à saúde. In: Campos FE, Werneck GAF, Tonon LM, organizadores. Vigilância sanitária. Belo Horizonte: Coopmed; 2001. p. 29-37. (Cadernos de Saúde, 4).

2. Teixeira CF, Paim JS, Vilasbôas AL. SUS: modelos assistenciais e vigilância da saúde. In: Rozenfeld S, organizador. Fundamentos da vigilância sanitária. Rio de Janeiro: Editora Fiocruz; 2000. p. 49-60.

3. Fortuna CM, Matumoto S, Pereira MJB, Mishima SM. Alguns aspectos do trabalho em saúde: os trabalhadores e os processos de gestão. Saúde Debate 2002; 26:272-81.

4. Campos GWS. Sobre a peleja dos sujeitos da reforma ou da reforma dos sujeitos em peleja. Saúde Soc 1992; 1:79-95.

5. Fundação de Economia e Estatística do Rio Grande do Sul. Índice de desenvolvimento social e econômico - IDESE. http://www.fee.tche.br (acessado em 17/Mar/2003)

6. Bardin L. Análise de conteúdo. Lisboa: Editora 70; 1977.

7. Minayo MCS. O desafio do conhecimento: pesquisa qualitativa em saúde. São Paulo: Editora Hucitec/Rio de Janeiro: ABRASCO; 2000.

8. Costa EA, Souto AC. Formação de recursos humanos para a vigilância sanitária. Divulg Saúde Debate 2001; 25:91-107.

9. Siqueira JCM. Gestão em vigilância sanitária. In: Campos FE, Werneck GAF, Tonon LM, organizadores. Vigilância sanitária. Belo Horizonte: Coopmed; 2001. p. 53-62. (Cadernos de Saúde, 4).

10. Luchese G. Globalização e regulação sanitária: os rumos da vigilância sanitária no Brasil [Tese de Doutorado]. Rio de Janeiro: Escola Nacional de Saúde Pública, Fundação Oswaldo Cruz; 2001.

11. Gottschald UG. Proposta de política de recursos humanos em vigilância sanitária. Porto Alegre: Divisão de Vigilância Sanitária/Secretaria da Saúde do Estado do Rio Grande do Sul; 2003.

12. Nogueira RP. Os recursos humanos e as políticas de gestão do Estado. http://www.pessoalsus.inf.br (acessado em 23/Mar/2003).
13. Pierantoni CR. As reformas do Estado, da saúde e recursos humanos: limites e possibilidades. Ciênc Saúde Coletiva 2001; 6:341-60.

14. Mishima SM, Pereira MJB, Fortuna CM, Matumoto S. Trabalhadores de saúde: problemas ou possibilidade de reformulação do trabalho em saúde? Alguns aspectos do trabalho em saúde e da relação gestor/trabalhador. In: Falcão A, organizador. Observatório de recursos humanos em saúde no Brasil: estudos e análises. Rio de Janeiro: Editora Fiocruz; 2003. p. 137-56.

15. Mendes EV. Distrito sanitário. São Paulo: Editora Hucitec/Rio de Janeiro: ABRASCO; 1995.

16. Merhy EE. Em busca do tempo perdido: a micropolítica do trabalho vivo em saúde. In: Merhy EE, Onoko R, organizadores. Agir em saúde: um desafio para o público. São Paulo: Editora Hucitec; 1997. p. 71-112.

17. Campos GWS. O anti-Taylor: sobre a invenção de um método para co-governar instituições de saúde produzindo liberdade e compromisso. Cad Saúde Pública 1998; 14:863-70.

18. Pasche DF. Gestão e subjetividade em saúde [Tese de Doutorado]. São Paulo: Faculdade de Ciências Médicas, Universidade Estadual de Campinas; 2003.

19. Costa EA.Vigilância sanitária, saúde e cidadania. In: Campos FE, Werneck GAF, Tonon LM, organizadores. Vigilância sanitária. Belo Horizonte: Coopmed; 2001. p. 14-27. (Cadernos de Saúde, 4).

20. Campos GWS. Subjetividade e administração de pessoal: considerações sobre modos de gerenciar o trabalho em equipes de saúde. In: Merhy EE, Onocko R, organizadores. Agir em saúde: um desafio para o público. São Paulo: Editora Hucitec; 1997. p. 229-36.

21. Campos GWS. Vigilância sanitária: responsabilidade pública na proteção e promoção da saúde. Brasília: Agência Nacional de Vigilância Sanitária, Ministério da Saúde; 2001.

22. Brasil. Lei n. 9782 de 26 de janeiro de 1999. Define o Sistema Nacional de Vigilância Sanitária, cria a Agência Nacional de Vigilância Sanitária, e dá outras providências. Brasília: Diário Oficial da União 1999; 27 jan.

Recebido em 14/Set/2004

Versão final reapresentada em 13/Set/2005

Aprovado em 21/Out/2005 